\section{Should Institutional Pharmacy Managers Maintain an Active Clinical Practice?}

\section{THE "PRO" SIDE}

A hospital pharmacy manager may be defined as an individual "who functions in a leadership capacity and is charged with the responsibility of a pharmacy department in a hospital or similar health care setting." Although the scope and responsibilities of the role may vary by hospital, for managers who work primarily on site in positions analogous to that of a clinical coordinator, there are several advantages to maintaining a clinical practice. Maintaining an active practice not only makes managers more effective and proficient in their role, but it strengthens their presence as a leader. This in turn increases both credibility and professional respect, while avoiding a "leadership crisis" and facilitating succession planning.

\section{Managers Who Maintain a Clinical Practice Are More Effective and Proficient in Their Role}

Clinical competency and knowledge are key attributes of hospital pharmacy managers, as highlighted in the position statement of the Canadian Society of Hospital Pharmacists, which posits that "the successful management of a hospital pharmacy department requires a combination of clinical drug therapy knowledge, practice experience, and management skill." ${ }^{1}$ Many practice-related issues are clinical in nature; therefore, managers with an active clinical practice may be able to more readily identify current issues and strategies to address them. Furthermore, unlike traditional hierarchical models (as typically seen in the business setting), hospitals and health care settings have an "inverted power structure", where active clinicians have greater influence than exclusively administrative managers on decisions regarding daily practice. $^{2}$

As such, clinical and managerial leadership skills are essential to initiate and maintain positive changes in the health care setting, and the combination may improve outcomes such as rates of error, patient readmission, and mortality. ${ }^{2,3}$ The benefit of combining clinical and managerial roles is further supported by the results of the Management Matters project. For this project, hospital managers were interviewed and evaluated with a tool that scored them from 1 ("worst practice") to 5 ("best practice") on 20 dimensions of management practice that fall under the broader domains of operations, performance, and talent management. The project findings indicated that hospitals with more clinically trained managers tended to achieve higher management scores, and hospitals with higher management scores performed better financially, achieved better clinical outcomes, and had higher levels of patient satisfaction. ${ }^{4}$ Higher management scores may be attributed to the ability of clinically trained managers to communicate in a language that clinical staff can understand and their first-hand appreciation for the clinical challenges that staff members face. ${ }^{4}$

\section{Maintaining a Clinical Practice Strengthens a Manager's Presence as a Leader}

Managers who maintain a clinical practice are more likely to be recognized as clinical leaders, which in turn enhances their ability to influence colleagues. This interplay between recognition and influence is reflected in Jane Doherty's report about clinical leadership, which expresses that health workers have more respect for and are more likely to follow leaders who remain engaged in clinical practice. ${ }^{5}$ Furthermore, hospital stakeholders value "visible leadership" (i.e., being a role model and leading by example), which is essential to influence and inspire colleagues to embrace practice changes focused on quality and safety improvement. ${ }^{6}$ Victor Lipman, with several years of Fortune 500 front-line experience, posed the question, "Why should leaders be outstanding role models who lead by example?" He answered his own question by stating that, "beyond the ethical considerations, there's an exceedingly practical one: it's effective. It makes people WANT to follow."7

Working as a clinician allows a manager to "walk in the shoes" of clinical staff, which gives the manager a better understanding and appreciation of the challenges that staff may face, and allows staff to have more genuine trust in and support of managerial decisions. As well, the manager-staff relationship becomes more collegial and less hierarchical. In the nursing setting, managers who did not maintain an active practice were deemed to be unapproachable and lacking the knowledge necessary to support nurses with clinical issues. ${ }^{8}$

\section{Being an Active Clinician Increases Both Credibility and Professional Respect}

To facilitate beneficial changes in the health care setting, those who are driving the changes must be seen by their colleagues as credible and clinically competent. ' Intuitively, pharmacy managers who maintain a clinical practice are deemed more credible, as they have the clinical competencies to enhance their managerial decision-making. This notion is supported by evidence from nonpharmacy settings. For example, physicians have stated 
that "the less [department heads] engage in clinical work, the harder it is for clinical leaders to maintain the respect of their clinician colleagues because ... this respect is based on their clinical knowledge and contributions, not on their formal position of authority". ${ }^{5}$ Department heads also risk losing credibility over time if they fail to maintain an active role in research, clinical practice, and continuing education. ${ }^{10}$ Moreover, in both medical and nursing practices, clinical leaders have more credibility and influence over colleagues than managers who have a strictly administrative role. ${ }^{8,10}$

The most effective form of managerial leadership encompasses both traditional hierarchical models and contemporary models wherein leadership is distributed among individuals on the basis of their skills, character traits, and relationships. ${ }^{6}$ Therefore, individuals in "hybrid" positions combining these models have greater credibility, professional legitimacy, and knowledge due to their clinical experience, but they also have the managerial authority to make important changes happen. ${ }^{6}$

\section{Clinical Leadership Is Necessary to Avoid a "Leadership Crisis" and to Facilitate Succession Planning}

William Gouveia, a former director of pharmacy at the Tufts-New England Medical Center, stated that to "attract pharmacy's best and brightest to leadership positions ... the pharmacy director or manager must serve as a clinical leader." 11 This statement was prompted by research results indicating that, while $80 \%$ of hospital pharmacy directors and $76 \%$ of middle managers planned to leave their positions in the next decade, only $30 \%$ and $63 \%$ of practising pharmacists and pharmacy students, respectively, demonstrated interest in filling these roles. ${ }^{12}$ The principal reason why pharmacists and pharmacy students were opposed to pursuing management positions was the prospect of having to give up their clinical practice. ${ }^{12}$ These findings gave rise to the concern that there may be a pharmacy "leadership crisis" if clinical practice is not incorporated into the role of pharmacy managers. ${ }^{12}$ Pharmacy managers who are active clinicians have more opportunities to serve as role models and to inspire students, residents, and colleagues to pursue leadership and managerial roles. ${ }^{11}$

\section{Conclusion}

Ultimately, institutional pharmacy managers who maintain an active clinical practice improve efficiency and proficiency by keeping their finger on the pulse of front-line issues and practices, attain a higher level of credibility and professional respect from peers and colleagues, and capitalize on being in a key position to lead by example and inspire future pharmacy leaders.

\section{References}

1. Canadian Society of Hospital Pharmacists. The role of the pharmacist as the head of hospital pharmacy services. Can J Hosp Pharm. 2005;58(5):299-303.

2. Ham C. Improving the performance of health services: the role of clinical leadership. Lancet. 2003;361(9373):1978-80.

3. Bohmer R. The instrumental value of medical leadership: engaging doctors in improving services. London (UK): The King's Fund; 2012 [cited 2016 Oct 7]. Available from: https://www.kingsfund.org.uk/sites/files/kf/ instrumental-value-medical-leadership-richard-bohmer-leadership-review 2012-paper.pdf

4. Dorgan S, Layton D, Bloom N, Homkes R, Sadun R, Van Reenen J. Management in healthcare: why good practice really matters. London (UK): McKinsey \& Company; London School of Economics and Political Science, Centre for Economic Performance; 2010 [cited 2016 Oct 7]. Available from: http://worldmanagementsurvey.org/wp-content/images/2010/10/ Management_in_Healthcare_Report_2010.pdf

5. Doherty J. Strengthening clinical leadership in hospitals: a review of the international and South African literature. Johannesburg (South Africa): University of the Western Cape, School of Government, The Municipal Services Project; 2013 [cited 2016 Oct 7]. Available from: https://www.wits.ac.za/media/ migration/files/cs-38933-fix/migrated-pdf/pdfs-5/Strengthening\%20clinical \%20leadership\%20in\%20hospitalsVers2.pdf

6. McKee L, Charles K, Dixon-Woods M, Willars J, Martin G. 'New' and distributed leadership in quality and safety in health care, or 'old' and hierarchical? An interview study with strategic stakeholders.J Health Serv Res Policy. 2013;18(2 Suppl):11-9.

7. Lipman V. You'll never go wrong leading by example. Jersey City (NJ): Forbes; 2014 [cited 2016 Oct 10]. Available from: www.forbes.com/sites/ victorlipman/2014/02/25/youll-never-go-wrong-leading-by-example/2/ \#7b0a79fe76f5

8. Stanley D. Role conflict: leaders and managers. Nurs Manag (Harrow). 2006;13(5):31-7.

9. Daly J, Jackson D, Mannix J, Davidson PM, Hutchinson M. The importance of clinical leadership in the hospital setting. J Healthc Leadersh. 2014;6:75-83.

10. Witman Y, Smid GAC, Meurs PL, Willems DL. Doctor in the lead; balancing between two worlds. Organization. 2011;18(4):477-95.

11. Gouveia W. Clinical leadership. Am J Health Syst Pharm. 2005;62(8):805.

12. White SJ. Will there be a pharmacy leadership crisis? An ASHP Foundation Scholar-in-Residence report. Am J Health Syst Pharm. 2005;62(8):845-55.

Laura Beresford, BSc(Pharm)

Renée Dagenais, BSC(Pharm), ACPR

Jenny Hong, BSC(Pharm), ACPR

Doctor of Pharmacy students

Sam Louie, BSc(Pharm)

Adjunct Professor

Faculty of Pharmaceutical Sciences

The University of British Columbia

Vancouver, British Columbia

Competing interests: None declared. 


\section{THE "CON" SIDE}

We are all familiar with the sayings "Lead by example" and "Walk a mile in someone else's shoes." However, when it comes to whether institutional pharmacy managers should maintain an active clinical practice, these sayings may not always hold true. Managers are responsible and accountable for providing leadership and direction to the department. They ensure that department policies and procedures comply with professional regulatory authorities. In addition, they direct the planning, implementation, maintenance, and evaluation of the practice model and standards for patient care services. The following are key considerations in support of institutional pharmacy managers not maintaining a current clinical practice: (1) to preserve patient safety, clinical pharmacists should have patient care as their main priority; (2) specializing in both clinical practice and management is not an effective or efficient approach to patient care; (3) to take care of patients, practitioners must first take care of themselves; and (4) pharmacy managers should lead through effective communication and delegation.

Take a moment and imagine that you are both an emergency department pharmacist and a hospital pharmacy manager. As you and the team discuss empiric antimicrobial therapy for a patient, your phone suddenly vibrates and distracts you from the conversation. Reading the message, you discover that your approval is required to obtain a life-saving nonformulary medication. When you turn your attention back to rounds, you find that the team has decided on the patient's pharmacotherapy without you. An hour later, you learn that the patient was started on an antibiotic to which the patient had a severe allergy, an allergy of which you (though not other members of the team) had been previously aware.

Trying to juggle multiple tasks and responsibilities, as in the preceding scenario, often stems from good intentions; however, it leaves us pulled in many different directions. We may find ourselves short on time and needing to cut corners, at the cost of patient safety, to complete mandatory tasks. Coviello and others ${ }^{1}$ derived a mathematical model illustrating that when the number of tasks increases, the effort that can be exerted on any one task decreases. Additionally, as we are all too aware, distractions lead to medication errors. Westbrook and others ${ }^{2}$ found a $12 \%$ increase in the occurrence of medication errors when nursing staff were interrupted once, and there were subsequent increases in errors with each successive interruption. Pharmacists have a responsibility to patients to minimize such errors by focusing on their clinical work.

Simultaneously specializing in both clinical care and management, which require vastly different skill sets, is not an effective or efficient approach to patient care. Specialization is a strategy used to maximize and improve outcomes in an increasingly complex health care delivery system..$^{3-5}$ Health care management should be recognized as a specialty in itself, given that advanced training is needed to equip people with the knowledge and skills required for these jobs. Conversely, lack of training in health care management has been identified as a growing concern. The CSHP national leadership survey of hospital pharmacy managers identified gaps in self-perceived competency in managerial skills due to lack of sufficient training in the undergraduate curricula and shortened residency rotations in administration relative to clinical rotations. ${ }^{6}$ With the need to specialize as managers, there is no time to concurrently specialize in a clinical practice area.

Another challenge is the time a practitioner must spend to stay current in their chosen clinical area to provide evidence-based care. For example, Majid and others ${ }^{7}$ estimated that about 8000 articles relevant to family practice are published monthly, and a family medicine practitioner would need to dedicate about 20 hours per day to stay abreast of new evidence. With less dedicated time in a clinical practice area, there is also less opportunity for application of new knowledge. Further splitting one's time to cover institutional pharmacy managerial duties would only exacerbate this already-challenging situation.

To take care of their patients, health care providers, including pharmacists, must first take care of themselves. A poor work-life balance affects more than workplace outcomes and organizational performance; it can have a substantial impact on personal life, family, and community involvement. ${ }^{8-10}$ Holding multiple job titles leads to longer hours worked every week. McClintock and others ${ }^{9}$ found that $50 \%$ of individuals with multiple job titles, but only $24 \%$ of those with a single job title, worked more than 50 hours per week. Health care professionals are also under tremendous pressure to cope with increasing workloads, a faster pace, and higher performance expectations. ${ }^{11}$ Across the health care sector, $26 \%$ of health care professionals reported that they often or always had difficulty coping with increased workload; the ranking was even higher for managers, at $28 \% .{ }^{11} \mathrm{~A}$ poor worklife balance is linked to fatigue, anxiety, and other adverse psychophysiological consequences that can affect the quality of care provided to patients and work-life dynamics. ${ }^{8,10}$ As one example, physician leaders have indicated that in addition to balancing all dynamics of clinical care, the requirement to balance the needs of the organization against the needs of the patient is an additional threat to their overall wellness. ${ }^{10}$

Pharmacy managers should lead through effective communication and through delegation of clinical duties to the pharmacy team. Many successful managers are also skilled leaders. ${ }^{12}$ Mark and others ${ }^{12}$ stated that a leader will "prioritize relationships and communication networks to better understand the needs of others, build social capital and stay current on events and information." By delegating delivery of clinical care to clinical pharmacists, a pharmacy manager can be a more effective leader who is better able to build relationships and who has more time to listen to members of the team. In addition, proper communication and delegation will reduce individuals' heavy 
workload, increase their job performance, and build positive team relationships. ${ }^{13}$

Institutional pharmacy managers with clinical experience have walked "a mile in someone else's shoes" or have "led by example" before taking on their managerial role. ${ }^{6}$ The manner in which our institutional pharmacy managers move up the "corporate ladder" gives them a solid understanding of and appreciation for clinical practice. However, for the many reasons discussed above, this does not mean that they need to maintain an active clinical practice. Rather, they must resist the temptation to become jacks of all trades if it means they will be masters of none.

\section{References}

1. Coviello D, Ichino A, Persico N. Time allocation and task juggling. Am Econ Rev. 2014;104(2):609-23.

2. Westbrook J, Woods A, Rob M, Dunsmuir W, Day R. Association of interruptions with an increased risk and severity of medication administration errors. Arch Intern Med. 2010;170(8):683-90.

3. Gourley DR, Fitzgerald WL Jr, Davis RL. Competency, board certification, credentialing, and specialization: Who benefits? Am J Manag Care. 1997;3(5): 795-801.

4. Ayanian JZ, Landrum MB, Guadagnoli E, Gaccione P. Specialty of ambulatory care physicians and mortality among elderly patients after myocardial infarction. N Engl J Med. 2002;347(21):1678-86.

5. Hillner BE, Smith TJ, Desch CE. Hospital and physician volume or specialization and outcomes in cancer treatment: importance in quality of cancer care. J Clin Oncol. 2000;18(11):2327-40.

6. Musing ELS, Wong M, Jackson L, Lee J, Slote C. A focus on leadership: CSHP's 2007 national leadership survey. Can J Hosp Pham. 2008;61(1):70-7.

7. Majid S, Foo S, Luyt B, Zhang X, Theng YL, Chang YK, et al. Adopting evidence-based practice in clinical decision making: nurses' perceptions, knowledge, and barriers. J Med Libr Assoc. 2011;99(3):229-36.

8. White M, Hill S, McGovern P, Mills C, Smeaton D. 'High-performance' management practices, working hours and work-life balance. BrJ Ind Relat. 2003;41(2):175-95.

9. McClintock W, Taylor N, Warren J. Effects of multiple job holding on the work-life balance. Labour Employ Work NZ. 2004;:245-50.

10. Wallace JE, Lemaire JB, Ghali WA. Physician wellness: a missing quality indicator. Lancet. 2009;374(9702):1714-21.
11. Lowe GS. High-quality healthcare workplaces: a vision and action plan. Hosp Q. 2002;5(4):4956.

12. Mark, SM, Saenz R, Clark JS, Stevenson JG. Leadership essentials for pharmacists. In: Pharmacy management, leadership, marketing and finance. 2nd ed. Burlington (MA): Jones and Bartlett Learning Company; 2014. pp. 23-37.

13. Millican E. Pharmacy management: if you want it done right, you don't have to do it yourself. Palm Springs (FL): Pharmacy Development Services; 2012 [cited 2016 Oct 22]. Available from: www.pharmacyowners.com/ blog/bid/79495/Pharmacy-Management-If-You-Want-it-Done-Right-YouDon-t-Have-to-Do-it-Yourself

Leanne Leung, BSC(Pharm), ACPR

Lucas Thorne-Humphrey, BSC(Pharm), ACPR

Stacey Tkachuk, BSC(Pharm), ACPR

Doctor of Pharmacy students

Dawn Dalen, BSP, ACPR, PharmD

Clinical Assistant Professor

Faculty of Pharmaceutical Sciences

The University of British Columbia

Vancouver, British Columbia

Dawn Dalen is also a Professional Practice Leader with Central Okanagan Pharmacy Services and a Clinical Pharmacist Specialist - Emergency Medicine with the Interior Health Authority, Kelowna, British Columbia.

Competing interests: None declared.

The Pro and Con articles for this issue's "Point Counterpoint" column were developed from a debate held in fall 2016 as part of the course "Advanced Pharmacy Administration: Topics in Contemporary Practice", Doctor of Pharmacy program, Faculty of Pharmaceutical Sciences, The University of British Columbia. 